\title{
A Reliable HPLC-DAD Method for Simultaneous Determination of Related Substances in TBI-166 Active Pharmaceutical Ingredient
}

\author{
Tingting Zhang, Wanting Yin, Bo Jin, Tong Li and Chen Ma* \\ Institute of Materia Medica, Chinese Academy of Medical Sciences and Peking Union Medical College, Beijing 100050, China
}

Received: 26 July 2018; accepted: 25 February 2019

\begin{abstract}
A sensitive, stability-indicating reversed-phase high-performance liquid chromatography with diode array detection (HPLC-DAD) method has been developed for the determination of TBI-166 and its 10 kinds of related impurities. Chromatographic separation was achieved on a Kromasil ODS column $(250 \mathrm{~mm} \times 4.6 \mathrm{~mm}, 5 \mu \mathrm{m})$, with a gradient elution of the mobile phase system consisting of acetonitrile and $1 \%$ ammonium formate solution (with $0.2 \%$ formic acid). The flow rate was $1.0 \mathrm{~mL} / \mathrm{min}$, and the detection wavelength was set at $251 \mathrm{~nm}$. The method was validated according to the International Conference on Harmonization (ICH) guidelines with respect to selectivity, linearity, limits, accuracy, precision, and robustness. The calibration curves were linear from LOQ to $150 \%$ of the specification limit of impurity with correlation coefficients not less than 0.999 . The limits of quantitation were between 0.123 and $0.257 \mu \mathrm{g} / \mathrm{mL}$. Accuracy for the related substances was estimated by the recovery ranged from $94.6 \%$ to $111.2 \%$. The method was proved to be reliable for the determination of related substances in TBI-166 bulk drug, which is essential and important in the quality control.
\end{abstract}

Keywords: TBI-166, HPLC-DAD, related substances, simultaneous determination, validation

\section{Introduction}

On a global scale, tuberculosis (TB) is a serious chronic infectious disease harmful to people's health, with 1.3 million new cases of deaths reported due to TB in 2017 [1]. It is noteworthy that multidrug-resistant tuberculosis (MDR-TB) remains a huge health threat to TB treatment [2-3]. Also in 2017, the World Health Organization announced the number of Rifampicin-resistance new illnesses was 558,000, and of these, $82 \%$ belonged to MDR-TB. Thus, it is very important to develop safer and more effective drugs against MDR-TB [4]. One clinical application drug for MDR-TB is clofazimine (CFM) [5-7]. However, this compound has disadvantages of being highly lipophilic $(\log P=5.39)$ and of extensive accumulation in skin and fat tissues, leading to an extremely long terminal half-life and undesirable side effects such as skin discoloration $[8,9]$. The negative characteristics of CFM limit its application and good effect on TB therapy. Scientists did a lot of structural modification work on CFM to get a more suitable drug for the treatment of MDR-TB [10].

TBI-166 $\left(\mathrm{C}_{32} \mathrm{H}_{30} \mathrm{~F}_{3} \mathrm{~N}_{5} \mathrm{O}_{3}\right.$, Table 1, CAS No.1353734-12-9) is found to be a lower lipophilic derivative of CFM and as potent as CFM in terms of efficacy [11]. Similar to CFM, TBI166 is widely active in vitro against various Mycobacterium tuberculosis strains, either sensitive or resistant. Minimum inhibitory concentration (MIC) against drug-sensitive clinical isolate ranges from 0.014 to $0.085 \mu \mathrm{g} / \mathrm{mL}$ for TBI-166 and is $0.12 \mu \mathrm{g} / \mathrm{mL}$ for CFM, while the activity against a panel of MDR strains ranges from 0.027 to $0.095 \mu \mathrm{g} / \mathrm{mL}$ for TBI-166 and from 0.108 to $0.240 \mu \mathrm{g} / \mathrm{mL}$ for CFM [12]. TBI-166 possessed lower lipophilicity $(\log P=4.52)$ and shorter plasma half-life than CFM in vivo, suggesting that it may accumulate less, which is very important to lower the toxicity and skin

* Author for correspondence: mach@imm.ac.cn. discoloration $[13,14]$. It means that TBI-166 may provide one more choice for treatment of MDR-TB. The research and development of TBI-166 as a preclinical candidate for TB treatment has been lasted for years [15]. Finished preclinical researches and approved for clinical trials in 2016, TBI-166 is undergoing Phase I trials now [16].

As to the development of TBI-166, there was no method reported for the quantitative determination of related impurities in TBI-166. It is significant to establish a method to control the quality, especially the assay of related substances in TBI-166 bulk drug. The established method must be fully validated $[17,18]$. According to the International Conference on Harmonization (ICH) guidelines of stability test [19], stress studies should also be carried out to investigate the selectivity of the method. Degradation impurities should be effectively separated by the established method.

In this report, a reliable high-performance liquid chromatography with diode array detection (HPLC-DAD) method for simultaneous determination of related substances in TBI-166 active pharmaceutical ingredient (API) was established and fully validated. Ten kinds of potential impurities of TBI-166 API are listed in Table 1, numbered based on their elution order, including raw materials, process intermediates, and process impurities.

\section{Experimental}

Chemicals and Reagents. Samples of TBI-166 API and 10 kinds of related substances Imp-1-Imp-10 were synthesized (purity $>96.0 \%$ ) and provided by Institute of Materia Medica, Chinese Academy of Medical Sciences and Peking Union Medical College (Beijing, China). HPLC-grade acetonitrile, acetic acid, formic acid, and ammonium formate were obtained from Fisher Scientific (Springfield, NJ, USA). Distilled water was prepared by Milli-Q system (Millipore,

This is an open-access article distributed under the terms of the Creative Commons Attribution-NonCommercial 4.0 International License (https://creativecommons.org/licenses/by-nc/4.0/), which permits unrestricted use, distribution, and reproduction in any medium for non-commercial purposes, provided the original author and source are credited, a link to the CC License is provided, and changes - if any - are indicated. 
TBI-166<smiles>COc1ncccc1Nc1cc2nc3ccccc3n(-c3ccc(OC(F)(F)F)cc3)c-2cc1=NC1CCC(OC)CC1</smiles><smiles>COc1ncccc1N</smiles>

Imp-2

Imp-3

Imp-4<smiles>O=[N+]([O-])c1ccccc1F</smiles><smiles>O=[N+]([O-])c1cc([N+](=O)[O-])c(F)cc1F</smiles><smiles>COc1ncccc1Nc1cc2nc3ccccc3n(-c3ccc(OC(F)(F)F)cc3)c-2cc1=NC1CCC(O)CC1</smiles>

Imp-5

Imp-6<smiles>Nc1ccc(OC(F)(F)F)cc1</smiles><smiles>FC(F)(F)Oc1ccccc1</smiles><smiles>COc1ncccc1Nc1cc2nc3ccccc3n(C)c-2cc1=N</smiles>

Imp-7<smiles>COc1ccc(N2c3ccccc3N=C3C=C(Nc4cccnc4OC)C(=NC4CCC(OC(=O)NC5CCC(OC)CC5)CC4)C=C3N2c2ccc(F)cc2)cc1</smiles>

E-10-(4-trifluoromethoxyphenyl)-3-(2methoxy-3-pyridyl) amino-2-(trans-4methoxycyclohexyl)imino-2,10dihydrophenazine

2-methoxy-3-aminopyridine

2- fluoro nitrobenzene

Difluorodinitrobenzene

(E)-4-((3-((2-methoxypyridin-3-yl)amino)-10(4-(trifluoromethoxy)phenyl)phenazin-2(10H)ylidene)amino)cyclohexanol

4-Trifluoromethoxyaniline

3-imino-N-(2-methoxypyridin-3-yl)-5-(4(trifluoromethoxy)phenyl)-3,5dihydrophenazin-2-amine

(E)-4-((3-((2-methoxypyridin-3-yl)amino)-10(4-(trifluoromethoxy)phenyl)phenazin-2(10H)ylidene)amino)cyclohexyl

(4-methoxycyclohexyl) carbamate 
Table 1. (contd.)

Imp-10

MA, USA). All other chemicals used were of analytical grade unless otherwise indicated.

Instruments and Chromatographic Conditions. The chromatographic separation was performed on a Shimadzu LC-20AT HPLC system (Shimadzu Corporation, Japan) equipped with a diode array detector. LC solution software was used for data collection and analysis. The column was a Kromasil ODS column $(250 \mathrm{~mm} \times 4.6 \mathrm{~mm}, 5 \mu \mathrm{m})$. The mobile phase comprising $1 \%$ ammonium formate with $0.2 \%$ formic acid (A) and acetonitrile (B) was delivered at a flow rate of $1.0 \mathrm{~mL} / \mathrm{min}$. The gradient program was as follows: 0-5 min, B, 35\%; 5-20 min, B, 35\%-60\%; 20-25 min, B, $60 \%$; 25-35 min, B, 60\%-85\%; 35-45 min, B, 85\%; 45$50 \mathrm{~min}, \mathrm{~B}, 85 \%-35 \%$; and $50-60 \mathrm{~min}, \mathrm{~B}, 35 \%$. The injected volume was $5 \mu \mathrm{L}$. The column temperature was $35^{\circ} \mathrm{C}$, and the multiple-detection wavelength was set at $251 \mathrm{~nm}$.

Preparation of Sample Solvent. The sample solvent was prepared by diluting $1 \mathrm{~mL}$ acetic acid to $1000 \mathrm{~mL}$ in acetonitrile.

Preparation of Stock Solutions for Method Validation. Stock solutions $(500 \mu \mathrm{g} / \mathrm{mL})$ of TBI-166 and 10 kinds of impurities, Imp-1-Imp-10, were prepared separately by dissolving appropriate amount in the sample solvent and were further diluted to study linearity, accuracy, precision, the limit of detection (LOD), and the limit of quantification (LOQ).

Preparation of Standard Solution, Recovery Solution and Sample Solution. The standard solution, containing $5 \mu \mathrm{g} / \mathrm{mL}$ ( $1 \%$ of the drug substance) of TBI-166 and 10 impurities, was prepared by diluting stock solutions $0.5 \mathrm{~mL}$ to $50 \mathrm{~mL}$ with the sample solvent. The recovery solution, $500 \mu \mathrm{g} / \mathrm{mL}$ TBI-166 spiked with impurities at a concentration of $2.5 \mu \mathrm{g} / \mathrm{mL}(0.5 \%$ of the drug substance), was prepared by dissolving suitable quantities of TBI-166 and 10 kinds of impurities in the sample solvent. This solution was used for estimating the accuracy result. The sample solution was prepared by dissolving TBI-166 API in the sample solvent to a concentration of $500 \mu \mathrm{g} / \mathrm{mL}$.

\section{Results and Discussion}

Method Development. The chromatographic parameters optimized included column type, mobile phase, and elution program. Initially, separation was tried on columns of different brands, like Symmetry $\mathrm{C}_{8}$, Xtimate $\mathrm{RP}_{8}$, Symmetry $\mathrm{C}_{18}$, Kromasil $\mathrm{C}_{18}$, and Inertsil- $\mathrm{C}_{18}$. Kromasil $\mathrm{C}_{18}$ showed good resolutions and peak symmetry for TBI-166 and the 10 kinds of impurities. Investigation of mobile phase was carried out using buffers like formic acid, ammonium acetate, and ammonium formate in varying combinations with methanol or acetonitrile. In addition, the introduction of ammonium formate was the major factor in achieving the desired resolution of closely eluting impurities and retention of TBI-166 peak. Finally, the mobile phase consisted of $1 \%$ ammonium formate (with $0.2 \%$ formic acid) and acetonitrile.

In view of the great difference of TBI-166 and its potential impurities in polarity, gradient elution is necessary to effectively separate all substances in one elution procedure. In the course of the investigation, Imp-1 is the fastest substance out of peak and is easily disturbed by solvent peak. By adjusting the initial proportion of gradient elution, acetonitrile (\%) was $55 \%, 50 \%, 45 \%, 40 \%$, and $35 \%$, and the retention time of Imp-1 was $3.4 \mathrm{~min}, 3.6 \mathrm{~min}, 3.8 \mathrm{~min}, 4.1 \mathrm{~min}$, and $4.4 \mathrm{~min}$, respectively. Imp-1 and solvent peak can be separated effectively by $35 \%$ acetonitrile. Therefore, acetonitrile-water phase of 35:65 was selected as the initial ratio (step 1) for gradient elution. Imp-2, Imp-3, Imp-4, Imp-5, and Imp-6 have similar retention time. Therefore, the proportion of acetonitrile was slowly increased at step 2 (5-20 min, acetonitrile, 35\%-60\%), which resulted in baseline separation of the 5 substances mentioned above. In step 3 (20-25 min, acetonitrile, 60\%), TBI166 and Imp-7 can be effectively eluted and baseline-separated. Then, acetonitrile (\%) was increased rapidly to $85 \%$, and the other three related substances (Imp-8, Imp-9, and Imp-10) could be eluted effectively in a suitable time. Under the developed method, resolutions of all substances were found to be more than 1.5 (Table 2), and the tailing factors of all the peaks were less than 1.1 .

Owing to the large differences in structure, ultraviolet (UV) absorption maximum wavelengths of Imp-1-Imp-10 were different from each other. Thus, the ultraviolet detection wavelength for HPLC method was also studied and chosen. TBI-166 and impurities (Imp-4, Imp-6, Imp-7, Imp-9, and Imp-10) all had maximum absorption at 279-285 nm, while the other 5 related substances 
Table 2. Method validation summary report

\begin{tabular}{|c|c|c|c|c|c|c|c|}
\hline Name & $\begin{array}{c}\text { RT } \\
(\min )\end{array}$ & RRT & Rs & $N$ & $T$ & $\begin{array}{c}\text { Precision } \\
(n=6)\end{array}$ & $\begin{array}{c}\text { Recovery } \\
(\%)\end{array}$ \\
\hline Imp-1 & 4.4 & 0.19 & - & 11,315 & 1.07 & 1.0 & 111.2 \\
\hline Imp-2 & 16.3 & 0.69 & 51.5 & 51,436 & 1.05 & 0.2 & 102.7 \\
\hline Imp-3 & 16.8 & 0.71 & 1.9 & 59,331 & 1.04 & 1.0 & 96.2 \\
\hline Imp-4 & 18.8 & 0.79 & 7.9 & 126,517 & 1.07 & 0.3 & 107.9 \\
\hline Imp-5 & 19.2 & 0.81 & 1.7 & 86,171 & 1.05 & 0.3 & 94.6 \\
\hline Imp-6 & 19.6 & 0.83 & 2.0 & 133,224 & 1.06 & 0.8 & 111.0 \\
\hline TBI-166 & 23.7 & - & 18.6 & 182,371 & 1.05 & 0.8 & - \\
\hline Imp-7 & 24.6 & 1.04 & 4.3 & 195,574 & 1.10 & 0.3 & 107.2 \\
\hline Imp-8 & 36.7 & 1.55 & 53.9 & 431,768 & 1.06 & 0.4 & 102.9 \\
\hline Imp-9 & 38.5 & 1.62 & 8.9 & 669,031 & 1.05 & 0.4 & 103.9 \\
\hline Imp-10 & 40.6 & 1.71 & 10.8 & 641,465 & 1.08 & 0.4 & 100.9 \\
\hline
\end{tabular}

had weak absorption at this range. At $251 \mathrm{~nm}$, TBI-166 and its 10 possible impurities were absorbed greatly, so $251 \mathrm{~nm}$ was chosen as the detection wavelength of the related substances.

Method Validation. The method was validated according to the ICH guidelines, including system suitability test, precision, linearity, limits, accuracy, solution stability, and robustness. The system suitability and selectivity were checked by injecting $500 \mu \mathrm{g} / \mathrm{mL}$ TBI-166 containing $0.5 \%$ $(2.5 \mu \mathrm{g} / \mathrm{mL})$ of all impurities (Figure 1). Method validation results are summarized in Table 2 .

System Suitability Test. System suitability testing is recommended as a significant component of any analytical procedure and can be used as part of the qualification. No sample analysis is acceptable unless the requirements of system suitability have been met. The major parameters are shown in Table 2, indicating that the results of system suitability test could conform to the acceptance criteria.

Forced Degradation Studies. Forced degradation study was performed to demonstrate the stability-indicating power and selectivity of the proposed method. About $1.0 \mathrm{mg}$ of TBI-166 was exposed in each degradation test. The stress conditions included acidic hydrolysis $(6 \mathrm{M} \mathrm{HCl}$, room temperature, for $30 \mathrm{~min}$ and $6 \mathrm{M} \mathrm{HCl}, 80{ }^{\circ} \mathrm{C}$, for $\left.30 \mathrm{~min}\right)$, base hydrolysis $(6 \mathrm{M}$ $\mathrm{NaOH}, 80{ }^{\circ} \mathrm{C}$, for $8 \mathrm{~h}$ ), oxidation $\left(30 \% \mathrm{H}_{2} \mathrm{O}_{2}, 80{ }^{\circ} \mathrm{C}\right.$, for $8 \mathrm{~h}$ ), thermal degradation $\left(80^{\circ} \mathrm{C}\right.$, for $8 \mathrm{~h}$ ), and photolytic degradation (5000 lx, for 10 days). Then, the samples were diluted with the sample solvent at a concentration of $40 \mu \mathrm{g} / \mathrm{mL}$, respectively.

TBI-166 was stable (content of TBI-166 decreased by less than $1 \%$ ) when exposed to thermal, base, photolytic, and oxidation stress situations, except for acidic stress. TBI-166 showed relatively low degradation $(0.6 \%)$ in the presence of $6 \mathrm{M}$ hydrochloric acid after 30-min exposure at room temperature. Repeating the acid hydrolysis test at a higher temperature of $80{ }^{\circ} \mathrm{C}$ increases the degradation content to $21.3 \%$ after 30 min exposure. The results of all the forced degradation studies have been exhibited in Figure 2. The degradation products can be completely separated from TBI-166 by the method. It is proved that the developed method is selective and can be used for the determination of related substances of TBI- 166 .

Precision. The precision was checked by injecting the standard solution six times and was established with relative standard deviation (RSD). Percentage RSD for peak area of each impurity was within $1 \%$ (Table 2 ). The result confirmed the good precision of the developed method.

Linearity. A linearity test solution was prepared by diluting the impurity stock solutions to the required concentrations. The content of each impurity should not exceed $0.5 \%$ of the drug substance by considering the toxicity and source. Thus, the solutions of Imp-1 to Imp-10 were prepared from the LOQ value to $150 \%$ at 6 concentration levels (LOQ, $0.1 \%, 0.25 \%$, $0.5 \%, 0.625 \%$, and $0.75 \%$ of the drug substance). The calibration curve was assayed from the peak area of analyte (y) against concentration $(x)$. The correlation coefficient obtained was greater than 0.999 for all impurities. The result showed an excellent correlation between the peak area and concentration of all impurities.

Limit of Detection and Limit of Quantification. LOD and LOQ were determined to evaluate the sensitivity of the HPLC analysis. LOD and LOQ were determined based on a signalto-noise ratio $(S / N)$ of 3 and 10, respectively. The LOD and LOQ of the 10 kinds of related substances are shown in Table 3. The LOQ of all impurities was not greater than $0.05 \%$ of the drug substance. Six separate solutions at the minimum concentration were prepared, and the RSD values were calculated from peak areas of 10 kinds of related substances. The precision at LOQ concentration for all impurities was below $2 \%$.

Accuracy. To evaluate the accuracy of the method, recovery solutions were prepared with 6 replicates and investigated. The percentage of recovery for each impurity was calculated and is showed in Table 2. The range of recoveries for the 10 impurities was $94.6 \%-111.2 \%$, indicating that all the values were acceptable, and the method was accurate for the measurement.

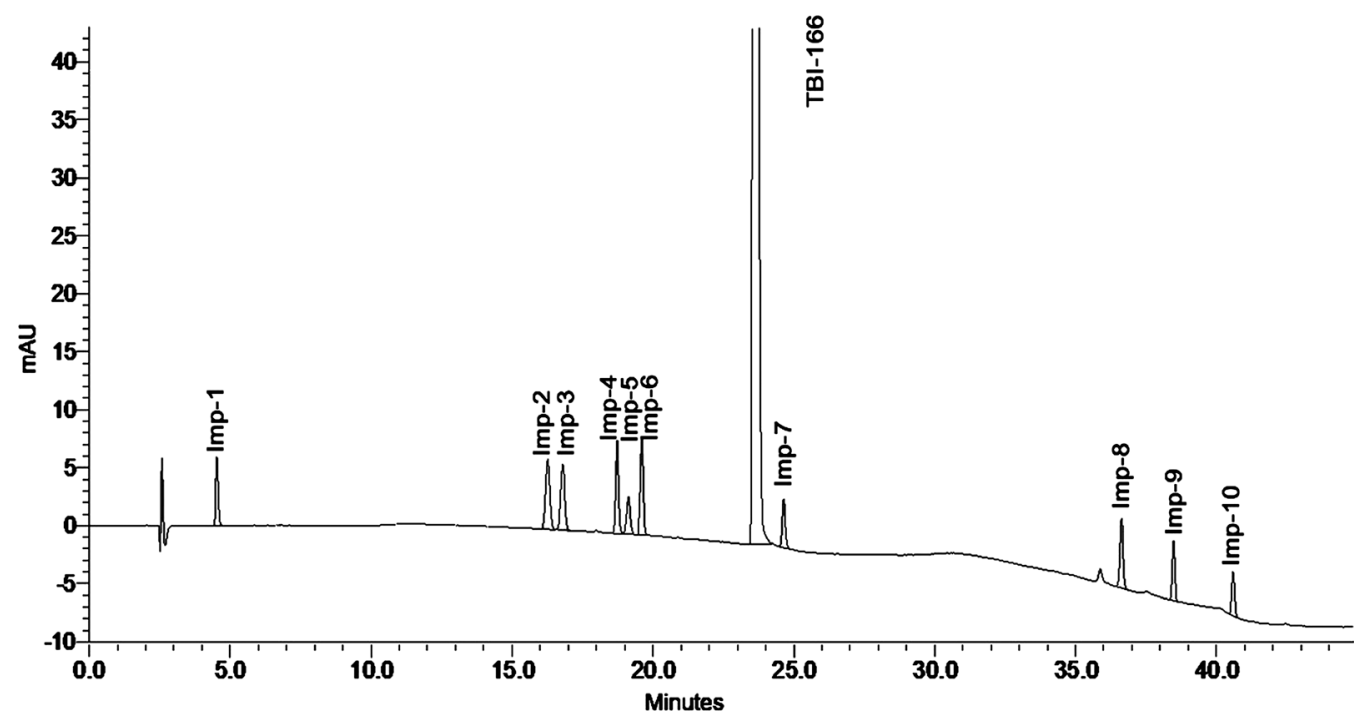

Figure 1. Chromatogram of $500 \mu \mathrm{g} / \mathrm{mL}$ TBI-166 spiked with $2.5 \mu \mathrm{g} / \mathrm{mL}$ impurities at $251 \mathrm{~nm}$ 


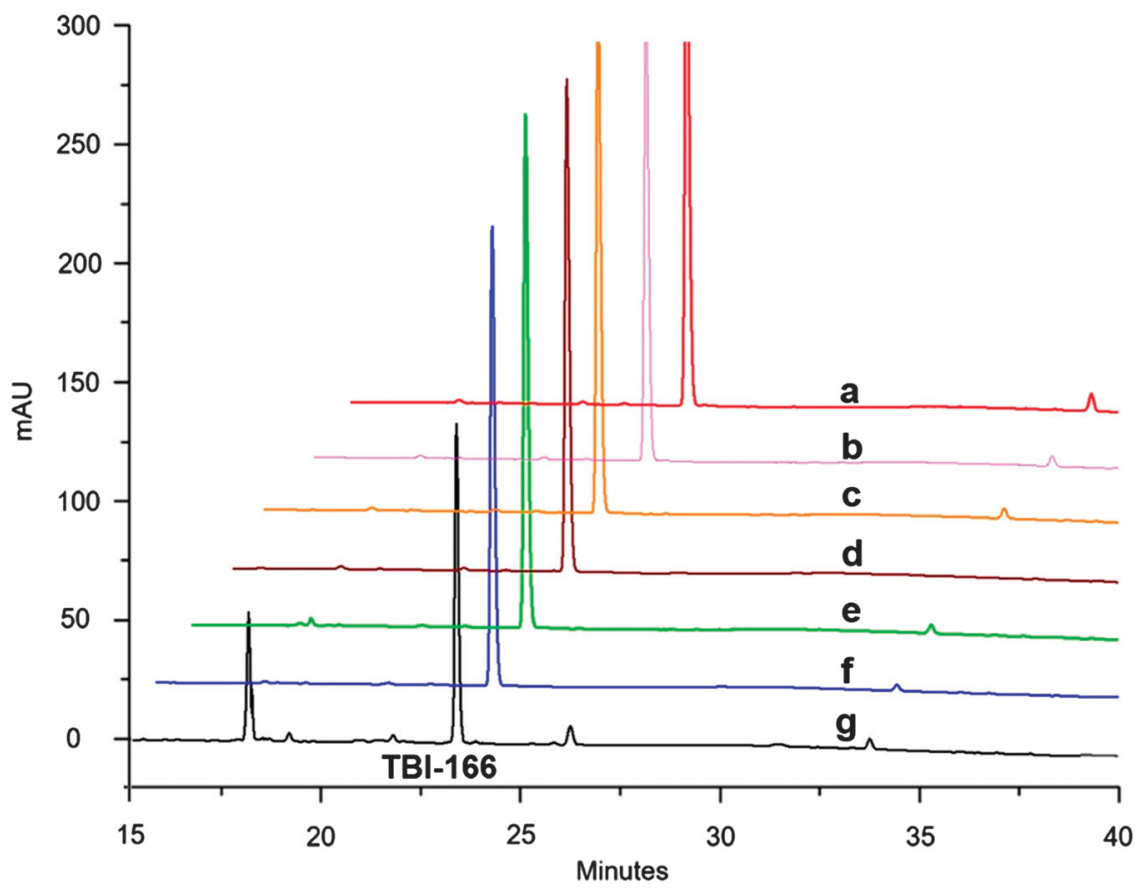

Figure 2. Typical chromatograms of samples under degradation studies: (a) TBI-166 API, (b) photodegradation, (c) thermal degradation, (d) oxidation degradation, (e) base degradation, (f) acidic hydrolysis at room temperature, and (g) acidic hydrolysis at $80{ }^{\circ} \mathrm{C}$ for 30 min

Robustness. The robustness of the method was evaluated by analyzing the standard solution, and the experimental conditions were deliberately changed (Table 4). All analyte

Table 3. Linear ranges, LOQ, and LOD of 10 related substances

\begin{tabular}{ccccc}
\hline Name & $\begin{array}{c}\text { Linear regression } \\
\text { equation }\end{array}$ & $r$ & $\begin{array}{c}\text { LOQ } \\
(\mu \mathrm{g} / \mathrm{mL})\end{array}$ & $\begin{array}{c}\text { LOD } \\
(\mu \mathrm{g} / \mathrm{mL})\end{array}$ \\
\hline Imp-1 & $\mathrm{y}=7691.1 x+7.0$ & 1.0000 & 0.211 & 0.079 \\
Imp-2 & $y=14988.2 x-310.5$ & 1.0000 & 0.218 & 0.082 \\
Imp-3 & $y=14804.7 x-1.8$ & 0.9958 & 0.134 & 0.054 \\
Imp-4 & $y=9910.6 x+76.5$ & 1.0000 & 0.214 & 0.080 \\
Imp-5 & $y=6264.8 x-97.8$ & 0.9992 & 0.251 & 0.092 \\
Imp-6 & $y=12155.9 x+296.5$ & 0.9992 & 0.123 & 0.049 \\
Imp-7 & $y=7265.5 x-144.8$ & 1.0000 & 0.248 & 0.089 \\
Imp-8 & $y=11367.1 x+8.6$ & 1.0000 & 0.198 & 0.074 \\
Imp-9 & $y=8570.0 x+381.8$ & 1.0000 & 0.205 & 0.077 \\
Imp-10 & $y=5961.4 x-72.6$ & 1.0000 & 0.257 & 0.093 \\
r, correlation coefficient. & & & \\
\hline
\end{tabular}

peaks were well separated, and the elution order of related substances and TBI-166 did not change. The results illustrated the robustness of the method.

Solution Stability. The solution stability test was performed on the standard and sample solutions at room temperature. Compared with the initial assay, the difference in peak areas of each related substance in the standard solution at each time point should be less than $2 \%$. Compared with the freshly prepared sample solution, the difference in impurities detected for sample solutions at each time point should be not greater than $0.1 \%$. The differences in standard solutions for 1 day, 3 days, and 7 days were $0.3 \%, 0.2 \%$, and $0.7 \%$, respectively. The differences in sample solutions for 1 day, 3 days, and 7 days were $0.02 \%, 0.04 \%$, and $0.07 \%$, respectively. The sample solutions were stable up to 7 days.

Samples Determination. Sample solutions of three batches of TBI-166 bulk drugs were analyzed to determine the related impurities (Table 5). Samples of TBI-166 contain two kinds of

Table 4. The results of robustness test

\begin{tabular}{|c|c|c|c|c|c|c|c|c|c|c|c|c|}
\hline \multirow[t]{2}{*}{ Parameter } & \multirow{2}{*}{$\begin{array}{c}\text { Changes of chromatographic } \\
\text { conditions }\end{array}$} & \multicolumn{11}{|c|}{ Rs } \\
\hline & & Imp-1 & Imp-2 & Imp-3 & Imp-4 & Imp-5 & Imp-6 & Imp-7 & TBI-166 & Imp-8 & Imp-9 & Imp-10 \\
\hline Initial condition & & - & 51.5 & 1.9 & 7.9 & 1.7 & 2.0 & 18.6 & 4.3 & 53.9 & 8.9 & 10.1 \\
\hline Initial mobile phase ratio & $40: 60$ & - & 40.3 & 1.8 & 7.2 & 1.5 & 1.9 & 17.1 & 4.2 & 54.1 & 9.0 & 10.5 \\
\hline$(v / v)$ acetonitrile- buffer & $30: 70$ & - & 50.5 & 1.7 & 7.6 & 1.6 & 2.1 & 17.4 & 4.1 & 50.2 & 8.7 & 10.4 \\
\hline \multirow[t]{4}{*}{ Composition of buffer } & $\begin{array}{c}0.8 \% \text { Ammonium formate } \\
(0.2 \% \text { formic acid })\end{array}$ & - & 52.3 & 1.8 & 7.5 & 1.7 & 2.1 & 17.6 & 4.0 & 49.8 & 8.0 & 10.3 \\
\hline & $\begin{array}{c}1.2 \% \text { Ammonium formate } \\
(0.2 \% \text { formic acid })\end{array}$ & - & 49.8 & 1.9 & 7.5 & 1.5 & 1.9 & 16.6 & 4.5 & 47.2 & 7.8 & 10.2 \\
\hline & $\begin{array}{c}1 \% \text { Ammonium formate } \\
(0.18 \% \text { formic acid })\end{array}$ & - & 44.7 & 1.7 & 7.9 & 1.5 & 2.0 & 19.1 & 4.2 & 53.5 & 7.5 & 10.5 \\
\hline & $\begin{array}{l}1 \% \text { Ammonium formate } \\
(0.22 \% \text { formic acid })\end{array}$ & - & 50.5 & 1.8 & 7.3 & 1.8 & 1.8 & 18.5 & 4.1 & 54.5 & 9.1 & 9.8 \\
\hline \multirow[t]{2}{*}{ Temperature $\left({ }^{\circ} \mathrm{C}\right)$} & $30^{\circ} \mathrm{C}$ & - & 51.2 & 1.6 & 8.2 & 1.6 & 1.7 & 18.3 & 3.9 & 53.9 & 8.6 & 9.2 \\
\hline & $40{ }^{\circ} \mathrm{C}$ & - & 50.8 & 1.5 & 7.7 & 1.9 & 2.2 & 18.1 & 4.1 & 54.1 & 8.8 & 8.7 \\
\hline Brands of column & $\mathrm{YMC} \mathrm{C}_{18}$ column & - & 50.4 & 1.8 & 6.7 & 1.7 & 2.1 & 17.6 & 4.2 & 50.4 & 9.0 & 8.9 \\
\hline \multirow[t]{2}{*}{$(250 \mathrm{~mm} \times 4.6 \mathrm{~mm}, 5 \mu \mathrm{m})$} & Phenomenex $\mathrm{C}_{18}$ column & - & 50.2 & 1.6 & 8.0 & 1.6 & 2.2 & 18.5 & 3.9 & 49.5 & 8.8 & 9.1 \\
\hline & $\mathrm{GL} \mathrm{C}_{18}$ column & - & 51.5 & 1.9 & 7.9 & 1.7 & 2.0 & 18.6 & 4.3 & 53.9 & 8.9 & 10.1 \\
\hline Brands of instrument & Agilent 1200 LC & - & 50.5 & 1.7 & 7.6 & 1.6 & 2.1 & 17.4 & 4.1 & 50.2 & 8.7 & 10.4 \\
\hline Rs, resolution. & & & & & & & & & & & & \\
\hline
\end{tabular}


Table 5. Impurity contents of TBI-166 bulk drugs

\begin{tabular}{lcccc}
\hline Production batch. & \multicolumn{3}{c}{ Single impurity(\%) } & Total content \\
\cline { 2 - 4 } & Imp-6 & Imp-7 & Unknown impurities & $(\%)$ \\
\hline Bach 1 & 0.19 & 0.11 & ND & 0.30 \\
Bach 2 & 0.053 & 0.13 & ND & 0.18 \\
Bach 3 & 0.077 & 0.13 & ND & 0.21 \\
$\quad$ ND, not detected. & & & \\
\hline
\end{tabular}

impurities, Imp-6 and Imp-7, which could be detected and determined by the established method.

\section{Conclusion}

The present reversed-phase HPLC (RP-HPLC) method was successfully developed and validated for the simultaneous determination of TBI-166 API and its 10 kinds of related substances. The validation data showed that the method was fully proven to be specific, linear, precise, accurate, robust, and stability-indicating. The proposed method could be used for determination of related substances in TBI-166 bulk drugs, as well as for quality control purposes.

Acknowledgements. This study was supported by the National Science and Technology Major Project of the Ministry of Science and Technology of China (No. 2015ZX09102007-002). Authors wish to thank Dongfeng Zhang and Haihong Huang from the Institute of Materia Medica, Chinese Academy of Medical Sciences and Peking Union Medical College, for providing samples of TBI-166 API and its potential impurities.

\section{References}

1. World Health Organization Global tuberculosis report 2018 World Health Organization, Geneva, Switzerland, 2018.
2. Gandhi, N. R.; Nunn, P.; Dheda, K.; Schaaf, H.S.; Zigno, M.; Zignol, M.; Soolingen, D. V.; Jensen, P.; Bayona, J. The Lancet 2010, 375, 1830-1843.

3. Palmer, B. D.; Thompson, A. M.; Sutherland, H. S.; Thompson, A. M.; Blaser, A.; Anderson, R. F.; Shinde, S. S.; Franzblau, S. G.; Ma, Z. K.; Denny, A. W.; Palmer, B. D. J. Med. Chem. 2010, 53, 282-294.

4. Lu, Y.; Zheng, M. Q.; Wang, B.; Fu, L.; Zhao, W. J.; Li, P.; Xu, J.; Zhu, H.; Jin, H. X.; Yin, D. L.; Huang, H. H.; Upton, A. M.; Ma, Z. K. Antimicrob. Agents. Ch. 2011, 55, 5185-5193.

5. Garrelts, J. C. DICP 1991, 25, 525-531.

6. Armand, V. D.; Maug, A. K. J.; Salim, M. A. H.; Das, P. K.; Sarker, M. R.; Daru, P.; Rieder, H. L. Am. J. Respir. Crit. Care Med. 2010, 182, 684-692.

7. Xu, H. B.; Jiang, R. H.; Xiao, H. P. Clin. Microbiolv. Infec. 2012, 18 , 1104-1110.

8. Kasim, N. A.; Whitehouse, M.; Ramachandran, C.; Bermejo, M.; Lennernäs, H.; Hussain, A. S.; Junginger, H. E.; Stavchansky, S. A.; Midha, K. K. Mol. Pharmaceutics 2004, 1, 85-96.

9. O'Connor, R.; O’Sullivan, J. F.; O'Kennedy, R. Drug. Metab. Rev. 1995, 27, 591-614.

10. Kamal, A.; Hari, B. A.; Venkata, R. A.; Sinha, R.; Yadav, J. S.; Arora, S. K. Bioorg. Med. Chem. Lett. 2005, 15, 1923-1926.

11. Zhang, D.; Lu, Y.; Liu, K.; Liu, B.; Wang, J.; Zhang, G.; Zhang, H.; Liu, Y.; Wang, B.; Zheng, M.; Fu, L.; Hou, Y.; Gong, N.; Lv, Y.; Li, C.; Cooper, C. B.; Upton, A. M.; Yin, D.; Ma, Z.; Huang, H. J. Med. Chem. 2012, $55,8409-8417$.

12. Giovanna, P.; Martina, C.; Sara, C.; Mariangela, B. Eur. J. Med. Chem. 2014, 86, 335-351.

13. Diana, Q.; Gayathri, N.; Richard, P.; James, A.T. Int. J. Infect. Dis. 2017, 56, 212-220.

14. Li, D.; Sheng, L.; Liu, X.; Yang, S.; Liu, Z. H.; Li, Y. Chromatographia 2014, 77, 1697-1703.

15. Liu, K.; Cooper, C. B.; Huang, H. H.; Li, C.; Liu, B. N.; Liu, Y.; Ma, Z. K.; Wang, J. B.; Yin, D. L.; Zhang, D. F.; Zhang, G.; Zhang, H. (New York, NY, US). Riminophenazines with 2-(heteroaryl) amino substituents and their anti-microbial activity. US Patent 8,716,292, May 06, 2014.

16. Working Group for New TB Drugs Home Page. https://www. newtbdrugs.org/pipeline/clinical (accessed Jan 30, 2019).

17. ICH Quality Q2 (R1), Validation of Analytical Procedures: Text and Methodology. http://www.ich.org/products/guidelines/quality/article/qualityguidelines.html (accessed Dec. 2016)

18. ICH Quality Guideline Q3A (R2), Impurities in new drug substance. http://www.ich.org/products/guidelines/quality/article/quality-guidelines.html (accessed Dec. 2016).

19. ICH Quality Guideline Q1A (R2), Stability testing of new drug substances and products. http://www.ich.org/products/guidelines/quality/article/ quality-guidelines.html (accessed Dec. 2016). 